\title{
Parental Factors Determining the Obesity Prevention Behaviour Among Thai Female Adolescents: A Cross-Sectional Study
}

\section{Rifat Hannan*}

Faculty of Public Health, Mahidol University, Thailand

*Corresponding Author: Rifat Hannan, Faculty of Public Health, Mahidol University, Thailand.
Received: July 06, 2021

Published: August 10, 2021

(C) All rights are reserved by Rifat Hannan.

\begin{abstract}
Purpose: The purpose of the study was to predict Thai female adolescents' obesity prevention behavior in terms of healthy diet and exercise using the framework based on Theory of planned behavior.
\end{abstract}

Design/Methodology/Approach: This study was conducted with a cross-sectional analytical design through an online survey over a period of 4 weeks in March - April 2020 among female First-year students of the Faculty of Public Health at Mahidol University, Thailand; aged between 18 - 22 years.

Findings: Parental norms followed by parents' marital status were the most important factors in predicting actual behavioral. Most of the students, (54.9\%) in spite of being underweight, found to be more cautious about maintaining their weight having fair obesity prevention behavior.

Research Limitations/Implications: The survey responses may be affected by a social desirability bias. The survey includes a nonprobability sample and results may not be generalized to all adolescents.

Practical Implications: The results may inform educators and policy makers in designing health communication interventions, particularly in making socializing agents aware of their role in fostering healthy eating behaviors in adolescents. As perceived behavioral control was the strongest predictor of behavioral intention, interventions and messages communicated to adolescents on healthy eating should aim to empower them with knowledge, ability and determination to eat more healthily.

Originality/Value: The study used a predictive, theoretical framework and questionnaire based on Theory of Planned Behavior (TPB) to investigate healthy eating and exercise behavior of the students.

Conclusion: Parental norms and Parents' marital status were associated with obesity prevention behavior. It is evident that to improve the obesity prevention behavior identified associated factors should be improved, for instance, health education and intervention and advocacy programs regarding healthy diet practice and exercise should be conducted involving their parents.

Keywords: Theory of Planned Behavior; Attitude; Subjective Norms; Perceived Controlled Behavior; Intention; Obesity; Adolescent

\section{Abbreviations}

TPB: Theory of Planned Behavior; BMI: Body Mass Index; WHO: World Health Organization; SEAR: Southeast Asian Region

\section{Introduction}

The World Health Organization (WHO) has recognized obesity as a global epidemic in 1997 [1]. The prevalence of obesity has doubled in children and quadrupled among adolescents over the last few decades [2]. In 2016, more than 1.9 billion adults were reported to be overweight Of these; Over 340 million children and adolescents aged 5 - 19 were overweight or obese worldwide [3]. Overweight and obesity have touched epidemic magnitudes in many Asian countries facing a shift towards younger age [4]. Obesity and overweight mostly result from a loss of balance 
between calories consumed and calories expended [5]. Practicing eating patterns and physical activity in adolescence can continue through adulthood. Increased intake of a high-calorie diet and lack of physical activities, sedentary lifestyles, changes in psychological conditions, such as anxiety, stress, depression even lack of sleep is considered as the common risk factors for overweight and obesity. Children are more likely to consume high-fat, sweetened, salty, calorie-rich, and micro-nutrient poor foods. Nutrition is one of the important elements for healthy living among teenagers and it should be given high priority. Therefore, promoting healthy eating patterns while conceding the improvement of nutritional status is essential for the future generation. Epidemiological evidence showed that menstrual abnormalities are very common in girls with excess body weight during adolescents that further plays an influential role in favoring ovulatory disorders even infertility [6]. So, controlling weight and prevention of obesity is very important for female adolescents. Late adolescents are the vital period of transition of life when individuals start preparing for a life of independent living thus it is censorious to establish lifestyle behaviors [6]. Peer influences significantly affect the development during adolescence, which includes behavioral attitudes [7]. However, weight control behaviors are shaped by bodyweight perception [8]. Bodyweight perception refers to one's personal appraisal of his/her weight as "underweight" or "normal weight" or "overweight" irrespective of actual body mass index (BMI) [8,9]. This discrepancy is also recognized as body image distortion. Youngsters sometimes misjudge their actual body size and express a certain degree of dissatisfaction which is sometimes also influenced by parental perceptions of children's bodyweight [10]. Obese and overweight individuals who distinguish themselves as flabbier are more expected to choose a healthy diet and exercise, taking into consideration the fact that, overweight individuals who do not consider themselves as overweight are less likely to involve in weight loss activities $[9,11]$. Evidence showed that some teenagers pick both healthy diet practice and exercise, but those who are not satisfied with their body image want to lose weight by means of laxatives, purging, and unhealthy fasting behaviors [12]. One's perception of body weight may not always signify reality. Weight control behavior is swayed by several influences including age, gender, parents, peers even media $[13,14]$. Females are more persuaded to identify themselves as overweight and get involved in unjustified weight loss practices [12]. Though weight reduction is desired in overweight and obese individuals, but redundant weight loss practices have possibly injurious outcomes for adolescents including deficiency of nutrients and hindrance to growth. Youngsters adopt activities and ideas that prevail among their friends, and continuous pressure to reduce weight has a detrimental impact on body weight perception [15]. Media relentlessly portrays images of slim and slender women which directs to the acceptance of these figures as a social norm and that precedes body size overestimation or underestimation [15]. Moreover, the period of childhood and adolescence is the formative years of shaping the lifestyle of an individual. So, the provision of a healthy diet and adequate exercise at this stage decreases the risk of different health conditions including obesity if primordial preventive measures can be provided through healthy dietary behavior and exercise.

In Thailand, childhood obesity is becoming a growing public health problem both in urban and rural areas. Thailand has experienced momentous transitions in the health sector and also economically since the last few decades and transformed progressively from a rural agricultural to an urban industrialized setting. All these have significantly altered their lifestyles, such as dietary practices and physical activities [16]. In Thailand, NCD mortality rates increased from $64 \%$ to $71 \%$ from 2000 to 2015 [17]. Once underweight was a problem among adolescents living in Thailand and overweight and obesity were rarely reported but with the improvement of economic status, the nutritional status has changed a lot. Now the status of being underweight is gradually declining with the consequential rise in the prevalence of overweight and obesity and the country is experiencing a double burden of malnutrition [17]. A trend towards the rising prevalence of overweight and obesity in children and adolescents, in both urban and rural areas, is a matter of concern. Overweight/obesity prevalence increased from $23.2 \%$ to $34.3 \%$ among Thai women over more than 10 years. A recent study has revealed the prevalence of obesity among female in Thailand is $24.1 \%$ [16]. However, maintaining body weight is an important matter of fact behind a healthy life. Given the knock-on effect of weight control behaviors, this needs to be assessed particularly among females.

Public health students are future health care professionals, dieticians, policymakers, and leaders. So, it is very important to assess their health-related behavior regarding the management of weight control. Very limited studies have emphasized about weight control practices or obesity prevention behavior among female public health students. The present study is therefore to investigate the attitude, subjective norms, perceived behavioral control, intention to control weight, and obesity prevention behavior among female first-year students of faculty of public health at Mahidol University, using the theory of planned behavior. The findings obtained from the study could be utilized to plan behavioral change communi- 
cation programs for adolescents and to help them control weight by exercise and dietary measures and thus support them to lead a healthy lifestyle.

The Theory of Planned Behavior is appropriate for our study as it can be used to assess certain behavior related to obesity prevention of adolescents' and the factors influencing that behavior. Individual attitude towards obesity prevention is composed of personal belief about obesity which can identify the students' attitude towards it. Subjective norms identify the opinion of other family members, social circle, and people they interact with, about dieting and exercising and the way their behavior get shaped by them to some extent. Perceived behavioral control can determine whether those adolescents have enough confidence and controllability to adopt a healthy dietary practice and good exercise behavior. Intention points out at the students' psychological readiness or eagerness to start healthy eating practices and to get involved with physical activities [18]. Our conceptual framework is based on this theory with a slight modification where the intention is also an independent determinant of the actual behavior. We made this modification to make the study easy to understand and less time consuming as a cross-sectional study because the application of TPB is mostly suitable for intervention studies.

\section{Materials and Methods \\ Study design}

This study was conducted with a cross-sectional analytical design on obesity prevention behavior among female First-year students of the Faculty of Public Health at Mahidol University, aged between 18-22 years.

\section{Study setting and participants}

Data were collected over a period of four weeks in the month of March-April 2020 in Mahidol University, Salaya, Thailand.

The study was conducted among female first-year students of the Faculty of Public Health at Mahidol University, aged between 18 - 22 years of the defined University in Thailand.

\section{Sample size determination and sampling technique}

The sample size was determined by the following formula:

$$
\begin{aligned}
& \mathrm{n}=\frac{Z_{\frac{a}{2}}^{2} \mathrm{p}(1-\mathrm{p})}{d^{2}} \\
& =\frac{1.96^{2} * 0.24 *(1-0.24)}{0.05^{2}} \\
& =281 \text { (approximately) }
\end{aligned}
$$

$$
\begin{aligned}
& \mathrm{n}=\frac{n *}{1+\frac{n *}{N}} \\
& =\frac{281}{1+\frac{281}{194}} \\
& =114.76+20 \% \text { drops } \\
& =138
\end{aligned}
$$

$\mathrm{n}=$ The desired sample size

$\mathrm{N}=$ Total no of female students in the first year, faculty of public health, Mahidol University $=194$

$\mathrm{Z}=$ Standard normal deviate for $\mathrm{Z}$ distribution, which corresponds to $95 \%$ confidence interval in normal distribution $=1.96$

$\mathrm{p}=$ Anticipated prevalence of Overweight/Obesity among Thai Women $=24.1 \%=0.24$ (Approx.)

$q=1-p=0.8$

$\mathrm{d}=$ Degree of accuracy $=0.05$

The sampling technique was purposive sampling. Data were collected online because of COVID 19 situation, so after a certain time, data collection was stopped before reaching the target sample size. $88 \%$ of the sample size took part in the survey.

\section{Inclusion criteria}

Female $1^{\text {st }}$-year students of the Faculty of Public Health, aged between 18-22 years who voluntarily consented to participate in the study will be included.

\section{Exclusion criteria}

Participants who were incapable for independent communication.

\section{Data collection instrument and procedure}

After the ethical approval from the Ethical Review Committee, Faculty of Public Health, the researcher asked for permission to the dean of the Faculty of Public Health. All the students were informed about the purpose and objectives of the study and to inform about the content of the questionnaire, data collection process, and context of the local condition online. The consent form and questionnaire were translated into the Thai language with the help of a Thai student who was enrolled in a master's program. The translated consent form and questionnaire were uploaded in google drive and an invitation was sent to female 1st-year public health students 
who were ready to participate in the study. It took approximately 30 minutes to complete the questionnaire. Data were collected for a period of four weeks. After that period data collection was stopped in spite of not getting an estimated sample size. Later the data were translated back in English. After that data analysis and statistical analysis were done. The data collection was handled by the primary investigator. The respondent had the full right either to participate or not or withdraw the study at any time of the study period. All of the answers were kept confidential. In any sort of report publication, any information that might make it possible to distinguish the respondents was not incorporated. After entering and analyzing the data set, all the datasets will be destroyed after one year.

\section{Data management and analysis}

Data processing and analysis were done using SPSS (statistical package for social sciences), version 18.0. The test statistics were used to analyze the data were descriptive statistics and Chi-square $(\chi 2)$ tests for association between dependent and independent variables.

\section{Ethical considerations}

This research protocol had been approved by The Ethical Review Committee for Human Research, Faculty of Public Health, Ma- hidol University (COA. No. MUPH 2020-040). Before starting the procedure of data collection, a full description of the researcher was provided to the respondents. All the personal information of respondents was kept confidential. This study consideration was followed by three main principles; beneficence, respect for human dignity and justice. The participation of respondents was strictly voluntary and confidential and was allowed to drop out during the survey. The respondents were treated with respect and thankfulness for their contribution.

\section{Results}

For overall obesity prevention behavior, the result showed most of the students (70.5\%) had fair behavior, while almost 15\% had equally poor behavior, and good behavior towards obesity prevention. it was similar like a study in Thailand, that showed $65.4 \%$ of the students had well-maintained obesity prevention behavior [19]. Mean \pm SD was $21.77 \pm 3.68$ (Table 1 ). The minimum behavior score was 14.0 , and the maximum behavior score was 34.0 out of 40.0. Two-thirds of them (60.7\%) had 3 meals every day. Half of them $(50.0 \%)$ consumed fruits More than 3 days in a week, on the other hand, only $1.6 \%$ never ate them, which indicated poor behavior. Half of the students walked 30 minutes for at least three days a week. Near about three-quarters (70.5\%) of students took part in any kind of sport for three to five days a week.

\begin{tabular}{|c|c|c|c|c|c|c|c|c|c|}
\hline \multirow{2}{*}{\multicolumn{2}{|c|}{ General Characteristics }} & \multicolumn{6}{|c|}{ Obesity prevention behavior } & \multirow{3}{*}{$\chi^{2}$} & \multirow{3}{*}{ p-value } \\
\hline & & \multicolumn{2}{|c|}{ Good } & \multicolumn{2}{|c|}{ Fair } & \multicolumn{2}{|c|}{ Poor } & & \\
\hline & & n & $\%$ & n & $\%$ & $\mathrm{n}$ & $\%$ & & \\
\hline \multirow{2}{*}{ Age } & $<20$ years & 14 & 14.3 & 70 & 71.4 & 14 & 14.3 & \multirow{2}{*}{0.210} & \multirow{2}{*}{0.900} \\
\hline & $\geq 20$ years & 4 & 16.7 & 16 & 66.7 & 4 & 16.6 & & \\
\hline \multirow{2}{*}{ Religion } & Buddhism & 16 & 15.1 & 75 & 70.8 & 15 & 14.1 & \multirow{2}{*}{0.271} & \multirow{2}{*}{0.873} \\
\hline & Islam and Christianity & 2 & 12.5 & 11 & 68.8 & 3 & 18.7 & & \\
\hline \multirow{2}{*}{$\begin{array}{l}\text { Parents marital } \\
\text { status }\end{array}$} & Married & 12 & 12.2 & 74 & 75.5 & 12 & 12.3 & \multirow{2}{*}{6.031} & \multirow{2}{*}{$0.049^{*}$} \\
\hline & Divorced/separated & 6 & 25.0 & 12 & 50.0 & 6 & 25.0 & & \\
\hline \multirow{3}{*}{ Type of family } & Nuclear Family & 8 & 11.3 & 52 & 73.2 & 11 & 15.5 & \multirow{3}{*}{7.365} & \multirow{3}{*}{0.118} \\
\hline & Single Parent Family & 5 & 35.7 & 6 & 42.9 & 3 & 21.4 & & \\
\hline & Extended Family & 5 & 13.5 & 28 & 75.5 & 4 & 10.0 & & \\
\hline \multirow[b]{2}{*}{ No of siblings } & $\leq 2$ & 15 & 14.6 & 72 & 69.9 & 16 & 15.5 & \multirow[b]{2}{*}{0.322} & \multirow[b]{2}{*}{0.851} \\
\hline & $>2$ & 3 & 15.8 & 14 & 73.7 & 2 & 10.5 & & \\
\hline \multirow{2}{*}{$\begin{array}{l}\text { Fathers' educational } \\
\text { status }\end{array}$} & Primary to Secondary & 9 & 14.1 & 47 & 73.4 & 8 & 12.5 & \multirow[t]{2}{*}{0.673} & \multirow[t]{2}{*}{0.714} \\
\hline & Bachelor and higher & 9 & 15.5 & 39 & 67.2 & 10 & 17.3 & & \\
\hline
\end{tabular}


Parental Factors Determining the Obesity Prevention Behaviour Among Thai Female Adolescents: A Cross-Sectional Study

\begin{tabular}{|c|c|c|c|c|c|c|c|c|c|}
\hline & & & & & & & & & 4 \\
\hline \multirow{2}{*}{$\begin{array}{l}\text { Mothers' educational } \\
\text { status }\end{array}$} & Primary to Secondary & 12 & 18.2 & 46 & 69.7 & 8 & 12.1 & \multirow{2}{*}{1.833} & \multirow{2}{*}{0.400} \\
\hline & Bachelor and higher & 6 & 10.7 & 40 & 71.4 & 10 & 17.9 & & \\
\hline \multirow{2}{*}{ Pocket money } & $<10000$ BAHT & 15 & 14.2 & 74 & 69.8 & 17 & 16.0 & \multirow{2}{*}{1.155} & \multirow{2}{*}{0.561} \\
\hline & $\geq 10000$ BAHT & 3 & 18.8 & 12 & 75.0 & 1 & 6.2 & & \\
\hline \multirow[t]{3}{*}{ BMI } & <18.5 (Underweight) & 4 & 15.4 & 20 & 76.9 & 2 & 7.7 & \multirow{3}{*}{1.855} & \multirow{3}{*}{0.762} \\
\hline & 18.5-22.9 (Normal) & 10 & 14.9 & 47 & 70.2 & 10 & 14.9 & & \\
\hline & >23(Overweight and obese) & 4 & 13.8 & 19 & 65.5 & 6 & 20.7 & & \\
\hline
\end{tabular}

Table 1: Association between general characteristics and obesity prevention behavior.

*Significant level $<0.05$.

It has been revealed that most of the students were underweight (54.9\%) but having fair obesity prevention behavior. The study revealed that there was a significant association between parent's marital status (Table 1), parental norms (Table 2) and obesity prevention behavior ( $p$-value< 0.05$)$. On the other hand, no statistically sig- nificant association was found between age of the respondents, type of family, no of siblings, parents education level, parents' occupation, monthly pocket money, BMI with obesity prevention behavior (p-value $>0.05)$.

\begin{tabular}{|c|c|c|c|c|c|c|c|c|c|}
\hline \multirow{3}{*}{\multicolumn{2}{|c|}{ Characteristics }} & \multicolumn{6}{|c|}{ Obesity prevention behavior } & \multirow{3}{*}{$\chi^{2}$} & \multirow{3}{*}{ P value } \\
\hline & & \multicolumn{2}{|c|}{ Good } & \multicolumn{2}{|c|}{ Fair } & \multicolumn{2}{|c|}{ Poor } & & \\
\hline & & $\mathbf{n}$ & $\%$ & $\mathbf{n}$ & $\%$ & $\mathbf{n}$ & $\%$ & & \\
\hline \multirow{3}{*}{ Attitude } & Positive & 6 & 12.0 & 35 & 70.0 & 9 & 18.0 & \multirow{3}{*}{2.458} & \multirow{3}{*}{0.652} \\
\hline & Neutral & 10 & 16.9 & 43 & 72.9 & 6 & 10.2 & & \\
\hline & Negative & 2 & 15.4 & 8 & 62.5 & 3 & 23.1 & & \\
\hline \multirow{3}{*}{ Parental norms } & Good & 4 & 50.0 & 3 & 37.3 & 1 & 12.5 & \multirow{3}{*}{11.068} & \multirow{3}{*}{$0.026^{*}$} \\
\hline & Fair & 8 & 15.4 & 39 & 75.0 & 5 & 9.6 & & \\
\hline & Poor & 6 & 9.7 & 44 & 71.0 & 12 & 19.4 & & \\
\hline \multirow{2}{*}{ Peer norms } & Fair to Good & 13 & 17.6 & 52 & 70.3 & 9 & 12.2 & \multirow{2}{*}{1.867} & \multirow{2}{*}{0.393} \\
\hline & Poor & 5 & 10.4 & 34 & 70.8 & 9 & 18.8 & & \\
\hline \multirow{2}{*}{$\begin{array}{l}\text { Perceived control } \\
\text { behavior }\end{array}$} & Good & 6 & 14.0 & 30 & 69.8 & 7 & 16.3 & \multirow{2}{*}{0.138} & \multirow{2}{*}{0.933} \\
\hline & Fair to Poor & 12 & 15.2 & 56 & 70.9 & 11 & 13.9 & & \\
\hline \multirow{3}{*}{ Intention } & Positive & 4 & 8.9 & 33 & 73.3 & 8 & 17.8 & \multirow{3}{*}{3.536} & \multirow{3}{*}{0.472} \\
\hline & Neutral & 9 & 15.5 & 41 & 70.7 & 8 & 13.8 & & \\
\hline & Negative & 5 & 26.3 & 12 & 63.2 & 2 & 10.5 & & \\
\hline
\end{tabular}

Table 2: Association of attitude, parental norms, peer norms, perceived control behavior, intention with obesity prevention behavior.

*Significant level $<0.05$.

\section{Discussion}

The aim of the study was to explore the factors associated with obesity prevention behavior in terms of a healthy diet and exercise among female adolescents using the conceptual framework based on modified theory of planned behavior. This study revealed that parental factors such as: marital status and parental norms can affect their actual behavior. 


\section{General characteristics}

Table 1 shows socio-demographic data. Most of the students (73.7\%) aged at 19 years, however, the average age of the students was 19.1. Eighty percent students' parents were married, whereas one-fifth $(19.7 \%)$ were divorced or separated. About one-third (30.3\%) of the respondents belonged to extended family whereas almost double the number of students (58.2\%) lived in the nuclear family. The majority of the students (84.4\%) had less than or equal to two siblings and one-quarter of them are the only child. Most of the fathers had high school degree and mothers had bachelors' degree. The average monthly pocket money was $6986.89 \pm 4940.7$ Baht with a minimum of 3000 Baht and a maximum of 30,000 Baht. Maximum students were underweight (54.9\%), 21.3\% of students were obese, only $12.3 \%$ of them were of normal weight, and $11.5 \%$ of them were overweight. The average BMI was $21.3 \pm 4.17$ while the minimum was 13.9 , and the maximum was 39.5 .

Despite being underweight, they found to be more cautious about maintaining their weight. It can be explained that the media relentlessly portrays slimmer figures as a symbol of beauty nowadays so females persuade misperception regarding their body image considering themselves as flabby and engage in unjustified weight loss practices like skipping meals, totally avoiding fat and sweets, or overdoing of exercises.

\section{Attitude}

About forty one percent of the students had a positive attitude, and one in ten students (10.7\%) had a negative and the rest had a neutral attitude towards obesity prevention behavior. This is similar with the result of another study in Bangladesh said that $35 \%$ of the students were having a positive attitude about their behavior regarding obesity prevention (20). There was no association found between attitude towards obesity prevention and actual behavior to prevent obesity. Moreover, those who had a neutral attitude had a fair obesity prevention behavior. In spite of being negative statements, most of the students (85.2\%) answered positively regarding eating sweets or chocolates elevates their mood, Two-third thinks skipping dinner can help in losing weight and $6.6 \%$ of the students strongly agreed that drinking lemon water can melt excess body fat. Most of the students (98.4\%) had a positive attitude towards exercising for at least 30 minutes for 3 days per week can help to maintain weight. Another study in Thailand also had similar findings to this study [19]. On the contrary $12.3 \%$ agreed that one does not need to exercise if eating less which is not a healthy habit.
The matter of concern is, about one-third of the respondents had misconceptions about diet and exercise behavior which indicated their perception regarding obesity prevention needs to be changed.

\section{Subjective norms}

This study identified patterns of eating, exercise, and obesity control behaviors were influenced by students' peer and parents crowd associations. Parental norms towards a healthy diet and exercise were found significantly associated $(p$ value $=0.026)$ with obesity prevention behavior. Whereas peer norms were not significantly associated with the outcome behavior. Half of the students had a poor level of parental norm, and only six percent students had a good level of parental norms. About a quarter of the students $(27 \%)$ answered regarding their parents that they "never" forced them to eat vegetables, "sometimes" influenced them to cut down fried, salty foods and "often" pushed them to perform exercise regularly for at least 30 minutes, three days per week. Almost half of the students (49.2\%) parents played least role to influence them to adopt healthy diet practice and exercise regularly which needs improvement. On the other hand, most of them (97.8\%) showed that their friends influenced them to exercise regularly. Parental norm is very important as children usually follow their parents. As a result, they naturally take after those habits which are prominent among their parents. A similar study by Beets et al. showed that parents influence their children's physical activities through a variety of methods which includes their own activity levels, attitude, and values toward activity (21). Parents play a significant role to develop a healthy eating practice and good exercise behavior as they are considered as an important footstep towards a greater understanding of which students may exhibit different forms of health-risk behaviors that leads to poor wellbeing outcomes in adolescence and adulthood, so parents' behavior should be changed in the first place.

\section{Perceived controlled behavior and Intention towards obesity} prevention

A study was done in a group of urban Native American youth to predict their healthy eating behavior and the result showed the presence of a significant association between perceived controlled behavior and actual behavior [22] but in this study perceived controlled behavior and intention, none of them had a significant association with obesity prevention behavior. It can be explained as the data was collected during the situation of COVID-19, which was not favorable for them to perform actually expected behavior. 
Near about half of them (47.5\%) had a neutral intention, $36.9 \%$ had a positive intention and fifteen students out of hundred had a negative intention to control weight. In both aspects, improvement is required. Our finding is similar to the study regarding urban native American youth to predict their eating behavior and the result showed no association between intention and actual behavior [22]. One of the similar studies by Dennison CM described in her study "Adolescent food choice: an application of the Theory of Planned Behavior" that attitudes and perceived controlled behavior were the components of the model those account for the most variation in intentions [23]. This can cause differences in intention and obesity prevention behavior.

\section{Limitations of the Study}

The research was carried out online which has several limitations including technical difficulties, poor survey design, uncertainty over the validity of the data and sampling issues, respondent's lack of online experience, etc. Usually, a paper survey has a higher response rate than an online survey, and chances of sampling bias and non-representativeness are also a matter of concern for internet-based survey research [24]. Though the response rate was higher (88\%) in compared to another study which was $78.9 \%$ [25]. Data obtained by structured questionnaires may limit data quality due to difficulty of recalling realistic information and the respondents may answer according to their knowledge which may not imply their real behavior. Since this study was conducted in a limited time and during the COVID-19 pandemic situation [26], confounding factors that may affect the obesity prevention behavior could not be controlled.

\section{Conclusion}

This study revealed that the parent's marital status and parental norms were the most important factors that determined actual obesity prevention behavior among late adolescents. The findings recognized a possibly significant zone of impact on student's eating, exercise, and stoutness control practices, that of their parent alliance and the environment of their home. In that capacity, the findings have suggestions for endeavors to improve students' wellbeing and diminish their health-hazardous practices So, the involvement of parents is highly recommended. The best outcome can be achieved if they can maintain a positive relationship with both parents despite any disruption and conflict. Several interventions, health literacy programs can be planned based on TPB that facilitate to adopt healthy eating and exercise behaviors to control weight and support to overcome major barriers. Such intercessions can be of great success by the friends' and parents' swarm af- filiations. Policymakers should enhance the access of their parents in different intervention programs.

\section{Acknowledgements}

The authors would like to thank the participants for their precious time and their generosity in sharing their experiences. They would also like to thank Ms. Kultida Rungrot and Ms. Doungtawan Sangngoen for helping in translation and data collection.

\section{Conflict of Interest}

None.

\section{Bibliography}

1. World Health Organization. "Obesity: preventing and managing the global epidemic". (2000).

2. Ng Marie., et al. "Global, regional, and national prevalence of overweight and obesity in children and adults during 19802013: a systematic analysis for the Global Burden of Disease Study 2013". The Lancet 384.9945 (2014): 766-781.

3. https://www.who.int/news-room/fact-sheets/detail/obesity-and-overweight

4. Ramachandran Ambady and Chamukuttan Snehalatha. "Rising burden of obesity in Asia”. Journal of Obesity 2010 (2010).

5. Das Sumon Kumar., et al. "Changing trend of overweight and obesity and their associated factors in an urban population of Bangladesh". Food and Nutrition Sciences 4.6 (2013).

6. Yang Kyeongra., et al. "Body mass index self-perception and weight management behaviors during late adolescence". Journal of School Health 84.10 (2014): 654-660.

7. Stankov Ivana., et al. "Overweight and obese adolescents: what turns them off physical activity?". International Journal of Behavioral Nutrition and Physical Activity 9.1 (2012): 1-15.

8. Mbarushimana Jean-Claude., et al. "The Relationship between Bodyweight Status and Weight Perception Explains Differences in Calories Ordered in a Food Choice Exercise". Nutrients 13.6 (2021): 1794.

9. Liechty Janet M. "Body image distortion and three types of weight loss behaviors among nonoverweight girls in the United States". Journal of Adolescent Health 47.2 (2010): 176-182.

10. Rodríguez Cecilia Colunga., et al. "Children and parents' perceptions of family functioning relating to childhood obesity". 
Advances in Applied Sociology 6.10 (2016): 330.

11. Owen Katherine B.., et al. "Self-determined motivation and physical activity in children and adolescents: A systematic review and meta-analysis". Preventive Medicine 67 (2014): 270279.

12. Yost Jennifer., et al. "Assessing weight perception accuracy to promote weight loss among US female adolescents: a secondary analysis". BMC Public Health 10.1 (2010): 1-11.

13. Robinson Eric. "Overweight but unseen: a review of the underestimation of weight status and a visual normalization theory". Obesity Reviews 18.10 (2017): 1200-1209.

14. Chen Li-Jung., et al. "Correlates of body dissatisfaction among Taiwanese adolescents”. Asia Pacific Journal of Clinical Nutrition 19.2 (2010): 172.

15. Balantekin Katherine N., et al. "Family, friend, and media factors are associated with patterns of weight-control behavior among adolescent girls". Eating and Weight Disorders-Studies on Anorexia, Bulimia and Obesity 23.2 (2018): 215-223.

16. Jitnarin, Nattinee., et al. "Prevalence of overweight and obesity in Thai population: results of the National Thai Food Consumption Survey". Eating and Weight Disorders 16.4 (2011): e242-e249.

17. Liangruenrom, Nucharapon., et al. "Physical activity and sedentary behaviour research in Thailand: a systematic scoping review". BMC Public Health 18.1 (2018): 1-24.

18. Ajzen Icek. "The theory of planned behavior". Organizational behavior and human decision processes". 50.2 (1991): 179211.

19. Page Randy $M$ and J Suwanteerangkul. "Dieting among Thai adolescents: having friends who diet and pressure to diet". Eating and Weight Disorders-Studies on Anorexia, Bulimia and Obesity 12.3 (2007): 114-124.

20. Bhuiyan Mejbah Uddin., et al. "Risk factors associated with overweight and obesity among urban school children and adolescents in Bangladesh: a case-control study". BMC Pediatrics 13.1 (2013): 1-6.

21. Beets Michael W., et al. "Parental social support and the physical activity-related behaviors of youth: a review". Health Education and Behavior 37.5 (2010): 621-644.
22. Fila Stefanie A and Chery Smith. "Applying the theory of planned behavior to healthy eating behaviors in urban Native American youth". International Journal of Behavioral Nutrition and Physical Activity 3.1 (2006): 1-10.

23. Dennison Catherine $M$ and Richard Shepherd. "Adolescent food choice: an application of the theory of planned behaviour". Journal of Human Nutrition and Dietetics 8.1 (1995): 9-23.

24. Sax Linda J., et al. "Using web surveys to reach community college students: An analysis of response rates and response bias". Community College Journal of Research and Practice 32.9 (2008): 712-729.

25. Saleh Amany and Krishna Bista. "Examining Factors Impacting Online Survey Response Rates in Educational Research: Perceptions of Graduate Students". 13.2 (2017): 63-74.

26. Sohrabi Catrin., et al. "World Health Organization declares global emergency: A review of the 2019 novel coronavirus (COVID-19)". International Journal of Surgery 76 (2020): 7176.

Volume 5 Issue 9 September 2021 (C) All rights are reserved by Rifat Hannan. 